\title{
Political Speech in Religious Sermons
}

\author{
Constantine Boussalis ${ }^{1}$, Travis G. Coan ${ }^{2}$, and Mirya R. Holman *3 \\ ${ }^{1}$ Department of Political Science, Trinity College Dublin \\ ${ }^{2}$ Department of Politics and Exeter Q-Step Centre, University of Exeter \\ ${ }^{3}$ Department of Political Science, Tulane University
}

\begin{abstract}
Religious leaders and congregants alike report high levels of political discussions in their churches. Yet, few opportunities emerge to directly observe political discussions in a wide set of religious settings. We examine the nature of these political discussions with a novel dataset of over 110,000 sermons. Using a computational text analysis approach and multiple forms of validation, we find political discussions in more than a third of religious sermons and that seven of ten pastors discuss political topics at some point. Common topics include the economy, war, homosexuality, welfare, and abortion. We then use a geographic process to link the sermon data to demographic and political information around the church as well as information about the church and pastor to evaluate variation of political discussion in sermons. We find that most pastors-across location and denomination—discuss most political topics, confirming the intertwined nature of religion and politics in the United States.
\end{abstract}

Keywords - religion and politics, sermons, elites, pastors, political communication, Protestantism, text analysis

\footnotetext{
*Corresponding author. We benefited from generous comments from Erin Cassese, Ray Block, Roland Kappe, and Slava Mikhaylov. Thomas Leeper and Arthur Spirling provided great advice about transparency and replication of our data. This paper was previously presented at the 2016 European Political Science Association meeting, the Amsterdam Text Analysis Conference, and the University College Dublin SPIRe Seminar Series. All errors remain our own.
} 


\section{Introduction}

Clergy routinely use political speech in religious environments to provide political information, shape opinions on political matters, and mobilized their parishioners. While scholarship often focuses on the political and religious experiences and attitudes of individuals (Jelen 1993; Margolis 2018), the importance of churches and clergy remains central to the study of politics and religion (Wilcox and Larson 2006). To date, a robust literature examines political activism in religious organizations primarily through surveys of religious leaders and congregants, case studies of particular churches, and qualitative work (Djupe and Gilbert 2002; Deckman, Crawford, and Olson 2008; Friesen and Djupe 2017; Guth et al. 1997; Glazier 2015), showing that pastors engage in high levels of political communication in churches and that congregants receive and process those messages.

Despite the importance of the politics of pastors, we know much less about the actual political content of religious sermons. We provide a large-scale evaluation of the political messages that Protestant pastors provide to their congregants via sermons. Sermons provide clergy with an opportunity rarely given to other elites: to routinely engage in both topic and focus through spiritual instruction (Djupe and Gilbert 2003; Calfano, Oldmixon, and Gray 2013). But how frequently do pastors use their sermons to discuss political issues? ${ }^{1}$ And which political issues do pastors discuss? To answer these questions, we examine the complete text of 110,423 sermons from 5,532 American religious (largely Protestant) leaders, using quantitative text analysis methods (Greene and O'Brien 2016; Boussalis, Coan, and Holman 2018; Grimmer and Stewart 2013).

We find that sermons routinely contain political discussions: $37 \%$ of all the sermons in the dataset discuss a political topic. Aggregate up to the pastor level, $71 \%$ of pastors in our dataset deliver at least one sermon with political content. Common topics include the economy, homosexuality, war, civil rights, welfare, and abortion. Our large-scale observational dataset builds on research that finds high levels of activism on core political issues through surveys of pastors and congregants (Deckman, Crawford, and Olson 2008; Djupe and Friesen 2018). We

\footnotetext{
${ }^{1}$ Here, we take a broad definition of discussion and use to cover political content of sermons, political talk, and other conceptualizations of how politics is framed by pastors in the church environment.
} 
then validate our descriptive findings through crowdsourcing (Benoit et al. 2016), as well as semantic and predictive validation procedures (Quinn et al. 2010).

Next, we build on extant literature (Djupe and Neiheisel 2008; Deckman, Crawford, and Olson 2008; Calfano and Oldmixon 2018) to examine which pastor, church, and location factors are associated with higher levels of political discussions generally and across specific political topics. We apply a novel approach to identify the community where our pastors preach by locating churches geographically and linking our sermons to census block and electoral precinctlevel information. We draw on this demographic and political information, plus denomination and pastor race and gender to evaluate the relationship between community characteristics and pastors' political discussions.

The results present a nuanced view of political discussions in religious environments. Pastors of most denominations, located in most communities, engage in some level of political discussion about most issues. Consistent with previous work, we find that Mainline Protestant pastors are more likely to discuss politics overall. Yet, contrary to expectations, Evangelical Protestant pastors are not more active on abortion, nor are they less active on social justice issues. And, Mainline pastors are more likely to talk about homosexuality (Thomas and Whitehead 2015). Overall, we find lower levels of political discussion than identified in most survey data (Djupe and Neiheisel 2008; Deckman, Crawford, and Olson 2008). Some of our findings emerge from the differences in data sources, including that our dataset provides an indepth evaluation of Evangelical pastors' behavior.

Our study addresses a key methodological concern in studying political discussions in ordinary speech: how to address class imbalance, or when topics of interest appear only rarely in a text, which is a widely acknowledged and persistent problem in text analysis (see Japkowicz and Stephen 2002). Here, we combine community-generated labels, crowdsourced codings, and a generative supervised learning model to overcome particular challenges associated with the detection of rare thematic content within large corpora, an approach that could be adapted by 
scholars studying a wide variety of types of text. ${ }^{2}$ We also offer a more precise approach to evaluate whether the community surrounding a church shapes the political communication of the pastor. Measures of geography commonly employed by political science research cover large areas and are arbitrarily assigned (e.g. counties or cities); we go further, by building far more specific measures of the community surrounding each church, and introducing methodological approaches that could be broadly applied. Taken together, our results and approach provide a rich detail on the interwoven nature of religion and politics in the United States.

\section{Political discussion in the church}

Do clergy discuss political issues? Which issues do they discuss? The extant research finds that most clergy report frequent discussions of political issues. In surveys, as many as $90 \%$ of pastors report engaging in issue-based political discussions through their sermons (Djupe and Gilbert 2002; Guth et al. 1997). Generally, church-based issue activism focuses on moral issues and social justice concerns. Social justice concerns, rooted in the Social Gospel movement, include liberal discussions of racial and gender equality, environmentalism, and welfare and social services, among others. Moral concerns, on the other hand, have their source in conservatism and focus on issues like abortion and homosexuality.

Surveys of clergy and the faithful and observational studies of sermons find frequent discussions of a wide variety of political issues. For example, in survey data, $98 \%$ of clergy in Djupe and Gilbert (2002) report addressing poverty and hunger and over $90 \%$ report addressing civil rights, environment, and education, with women's rights, unemployment and the economy, and gay rights also receiving significant attention. On moral issues, most pastors reporting high levels of discussions of family issues, homosexuality, capital punishment, and abortion (Djupe and Gilbert 2002). Similar levels of political discussions were identified in observations of 95 different worship services (Brewer, Kersh, and Petersen 2003). In evaluating what the religiously faithful remember hearing, Scheitle and Cornell (2015) find that $62 \%$ of respondents reporting hearing about abortion and just under half heard discussions about homosexuality and the

\footnotetext{
${ }^{2}$ We also make the software available to the broader research community to assist in estimating supervised generative models for political text
} 
environment.

How might looking at the text of a large set of sermons line up or depart from the extant findings on pastor political activism? One possibility is that some (or all) pastors overreport their political activism in surveys because of social desirability biases (Presser and Stinson 1998), including that pastors believe that they should be discussing political issues more than they actually do. For example, pastors might feel pressure to report that they discuss poverty and the economy at higher rates than they do. Another possibility is that surveys overcount political discussions because of who is sampled in these surveys. For example, some of the samples used, including the surveys of ECLA and mainline Episcopal clergy (Djupe and Gilbert 2003), may be more liberal (and thus more political active on some issues) than other denominations of clergy in the United States. Overcounting may also occur if pastors underreport the extent to which they engage in political discussions because they are concerned with how those reports will be received.

Using sermons to evaluate political speech in sermons

To assess the degree to which political discussions in sermons map onto or depart from survey and observational data, we face a methodological challenge: identifying these discussions. Past scholarship generally estimates the frequency of political speech in sermons by self-reports from clergy and members of congregations, or direct observation by researchers of religious environments (Brewer, Kersh, and Petersen 2003; Guth et al. 1997). We provide an alternative, direct measure of religious speech: the content of sermons themselves. More specifically, we utilize a large set of sermons posted on SermonCentral.com (Woolfalk 2013), which is an online resource for Christian pastors to share sermons and religious leadership information with each other. SermonCentral itself claims to be the "largest" and "most popular" sermon research site in the world, with "Over 250,000 church leaders" visiting the website every week. ${ }^{3}$

On the website, pastors provide information about themselves, including their denomination, and information (include the name and address) about their church and a profile picture. Contributors label sermons with the key topics covered in the text (called "tags"), as well

\footnotetext{
${ }^{3}$ For more information on SemonCentral, see: https://bit.ly/2PY9OKy
} 
as the scripture referenced in the sermon. There is also a social aspect to SermonCentral, as other members of the community can add additional labels and scriptures, and comment on and rate the sermons. Like other social networks, we expect that SermonCentral is neither "democratic nor undemocratic," in that it replicates existing inequalities in participation (Barberá and Rivero 2015; Evans, Cordova, and Sipole 2014). We do not know why pastors participate on the website, beyond what the pastors themselves say: they want an online community where they can share their sermons, communicate with other pastors, and learn from other religious elites.

\section{Data: a large corpus of religious text}

To examine patterns in the sermon data, we collected, cleaned, coded, and analyzed the posted sermons. In September and October 2015, we harvested the full text and meta-data for each sermon, resulting in a collection of 134,531 sermons from 6,716 unique contributors.

Figure 1: Distribution of churches in dataset

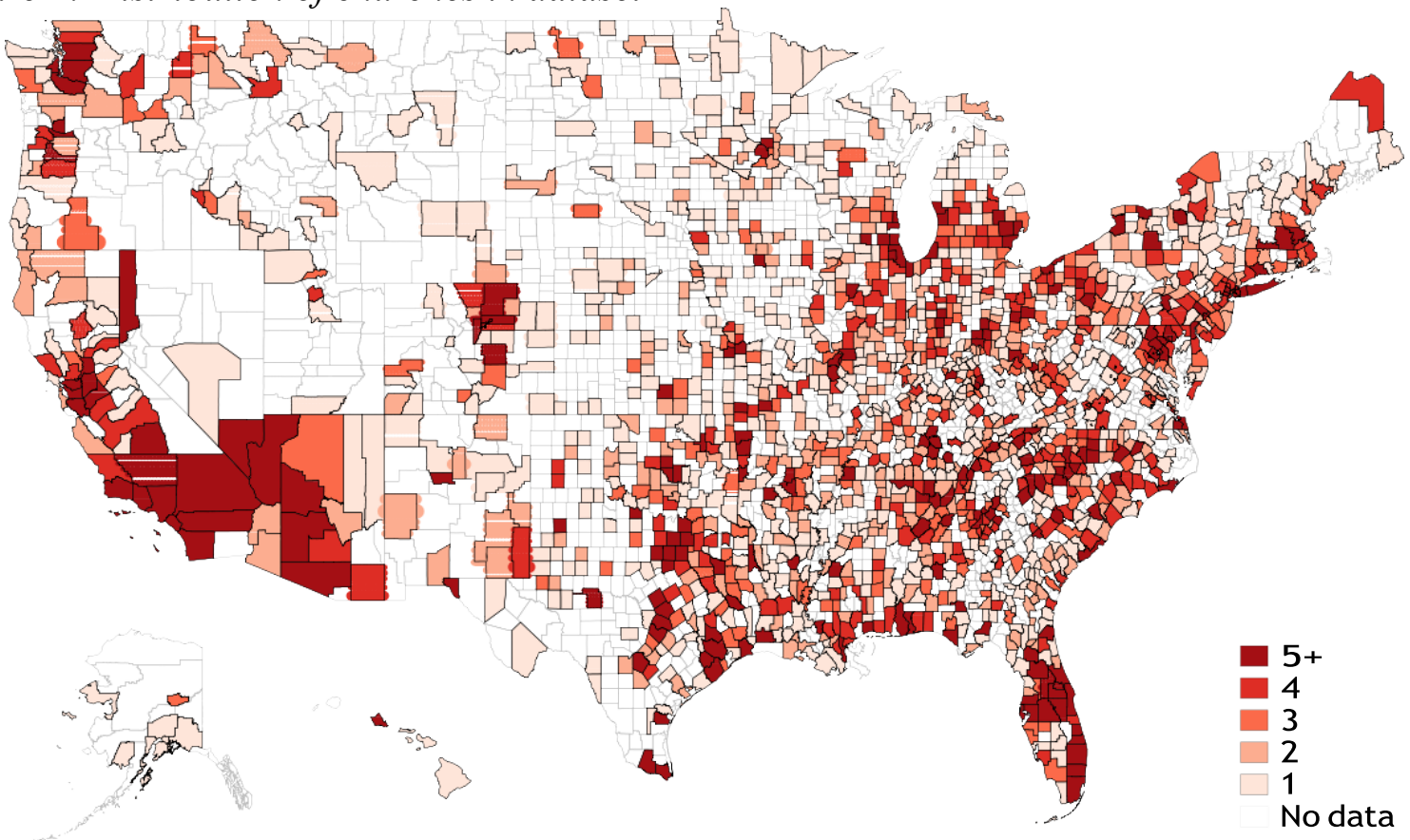

. This figure displays the number of churches included in our sample by county.

We pruned out sermons from churches located outside the United States or without a listed address, not in English, or from severely under-represented denominations (namely, Catholics and 
Mormons $^{4}$ ) We are left with 110,423 sermons from 5,532 pastors, covering the period October 2000 to September 2015. Figure 1 provides the geographic distribution of our churches. Within our sample, the average number of sermons uploaded per pastor is $19(\mathrm{SD}=60)$.

The sermons uploaded to SermonCentral are a convenience sample. We acknowledge that this sample is not representative, but we have reason to believe the pastors and their church locations look like U.S. Protestant churches and pastors. We benchmark our churches against the National Congregations Study, and the locations of our churches against the U.S. Census and Religious Census. Our sample provides a departure from previous studies as we can provide a more robust discussion of conservative denominations. Table 1 provides compares our sample to the U.S. population, a religious census, and on political variables (see Appendix).

Table 1: How representative is the sample?

Table 1: Benchmarking our sample against U.S. counties

\begin{tabular}{|c|c|c|c|}
\hline Variable & Sample counties & All U.S. counties & Source \\
\hline Median population & 167,641 & 96,024 & U.S. Census (2010) \\
\hline Median income & $\$ 50,690$ & $\$ 49,566$ & \\
\hline Poverty rate for families & 12.36 & 12.31 & \\
\hline Median age & 37.8 & 38.6 & \\
\hline$\%$ White & 75.7 & 77.7 & \\
\hline$\%$ with HS diploma or higher & 85.7 & 85.5 & \\
\hline Total rate of adherence & 498 & 504 & U.S. Religious Census (2010) \\
\hline Mainline Protestant rate of adherence & 84 & 95 & \\
\hline Evangelical rate of adherence & 229 & 227 & \\
\hline Party ID (7pt) & 3.9 & 3.9 & CCES (2012) \\
\hline Religious importance (7pt) & 3.1 & 3.1 & \\
\hline Church attendance $(5 \mathrm{pt})$ & 3.3 & 3.3 & \\
\hline$\%$ Obama vote 2008 & 46.2 & 44.9 & Leip's Atlas \\
\hline
\end{tabular}

The counties in our dataset resemble U.S. counties in terms of racial composition, income, poverty rate, education, and age, while our sample's counties have a higher average population than the average U.S. county. Our total rate of adherence is slightly lower than the average U.S. county, as is the mainline Protestant rate of adherence, while our sample counties have a higher rate of Evangelical adherence than the average. We also comparing the counties in our dataset that also appear in the 2012 Cooperative Congressional Elections Study (CCES) to counties in

\footnotetext{
${ }^{4}$ There is almost no representation from Catholic or Mormon religious leaders. Given the under-representation of these groups, we drop these sermons from our sample.
} 
the CCES overall and find strong similarity in political party identification, the importance of religion, and church attendance, as well as on levels of support for Obama in 2008. These comparisons give us confidence that the churches in our dataset are located in demographically, religiously, and politically representative places.

To evaluate the ways that our sample resembles American Christian elites, we compare the location, denomination, and demographics of our pastors to the 2012-2013 National Congregations Study (NCS) and to the 2010 Religious Census. We find that our pastors resemble those pastors in the NCS relatively well. Evangelicals make up just under $64 \%$ of our pastors. In comparison, Evangelicals make up $67.2 \%$ of pastors in the NCS. In turn, mainline Protestants are $22 \%$ of our pastors and $20.3 \%$ of the pastors in the NCS.

\section{A Computational Approach to Identifying Political Discussions in Sermons}

The large size of our data provides an ideal opportunity to use scalable, computer-assisted methods to accurately and reliably classify political text (Grimmer and Stewart 2013; Aaldering and Van Der Pas 2018; Boussalis, Coan, and Holman 2018) including discussions by political elites (Grimmer 2013; Greene and O'Brien 2016). What is the best strategy for extracting political references from the corpus? One approach would be to construct a dictionary of theoretically-informed political keywords that would be used to calculate the prevalence of these keywords in our corpus of sermons. Yet, the nature of political discussions and religious texts presents technical difficulties for classifying politics using dictionary-based methods as many political keywords also have a religious meaning. For instance, consider the word "election." While election is certainly present in discussions of electoral politics, it also appears quite regularly in the Christian concept of the "elect" or God's chosen people.

If simple dictionary-based methods are inadequate, what other tools are available to classify political speech in a large collection of sermons? The field of machine learning offers a wide range of statistical tools for meeting this objective. The most common approach to supervised learning methods (see Grimmer and Stewart 2013, pg. 9) relies on discriminative models to predict categories or "classes." When the underlying data takes on a simple structure, 
these models have been shown to be a superior tool to the other major classification approach, namely generative models ( $\mathrm{Ng}$ and Jordan 2002). Yet, discriminative models may perform poorly when some classes are much more prevalent than others - referred to as class imbalance-and there are a large number of potential classes from which to choose (Rubin et al. 2012). Unfortunately, these properties are defining features of our sermon corpus (and many other politically oriented texts). Political language is infrequent (and linguistically diverse) when compared to discussion of core religious themes. Even a cursory glance at the SermonCentral corpus reveals that the majority of sermon discusses religious rather than political matters. Moreover, past scholarship demonstrates that American pastors discuss a large number of political topics when preaching to their congregants. For instance, Djupe and Gilbert (2002) identify 16 broad topics in their survey of Lutheran and Episcopalian ministers. Even this small number pushes the limits of what is considered a reasonable level of performance for discriminative models (Liu et al. 2005; Rubin et al. 2012).

Our approach addresses these challenges by combining the pastor-generated tags with human coding and a generative statistical model for text data. The user-generated labels capture the key topics or themes associated with each sermon. A sermon entitled "Bringing America Back to God" was tagged by users of SermonCentral with the following labels: economy, America, revival, socialism, morality, and the scripture Judges 1:1-21:25. Using the labels as a starting point for classification is easy, given that they capture the primary political themes described in past literature. Nevertheless, labels must be standardized prior to analysis and we had to determine which labels are actually political. Given the free-form nature of the labels and the size of the sermons corpus, we harvested the list of tags $(N=19,525)$ and employed crowd-sourcing to reduce the label set from 19,525 to 231 tags that could be about politics (Benoit et al. 2016), a process described in the Appendix. Next, we assess each of the 231 labels by reading the content of five sermons associated with each label. Finally, we aggregate labels into 25 themes that discuss common political topics, such as combining the "patriotism" and "4th of July" 5

\footnotetext{
5 The authors independently coded subtopics into themes. Inter-coder reliability for the aggregate categories was quite high, with a Cohen's kappa of 0.88 . All remaining differences were reconciled via committee. Finally, a research assistant, blind to the hypotheses, replicated this aggregated coding scheme, resulting in a Cohen's kappa of 0.89
} 


\subsection{Learning about political speech from community-generated labels}

After we identify the relevant political labels, we face a challenge: we cannot directly use the standardized labels to measure political communication by, for example, counting the number of times a particular label appears in the corpus. But the observed labels often fail to be attached to politically relevant sermons. For instance, a sermon entitled "What about homosexuality?" is clearly about homosexuality, yet, the only generic tag on the sermon is "sin bondage to" is applied. Put simply, while sermons tagged with political labels almost always contain politically relevant content, the converse is not necessarily true: just because a sermon does not have a political tag does not mean it does not contain political content.

To apply these missing labels, we rely on a generative model to infer missing labels from observed labels, employing a supervised extension of the well-known latent Dirichlet allocation (LDA) outlined in Rubin et al. (2012)). The labelled or "flat" LDA provides a simple, hierarchical Bayesian model for the random process responsible for "generating" a particular text. After performing a series of text pre-processing steps,${ }^{6}$ we estimate the labelled LDA, first training the model using $k=500$ iterations. Next, we treat all the sermon labels as missing and infer their topics based on the parameter estimates from the trained model. The topic model provides to us a set of topics, which we then label based on the most probable keywords for each topic and by reading sermons with large estimated proportions of a given topic. Once we estimated the probability of a given political theme in each sermon, we then calculated the relative prevalence of each political topic in the corpus.

\section{The Political Topics in Sermons}

How often do political topics occur in sermons and which political topics are discussed most

\footnotetext{
${ }^{6}$ Given the large corpus size and the fact that generative models, such as the labelled LDA, are computationally expensive, we took a series of pre-processing steps to prune the corpus vocabulary. Specifically, we (1) lowercase all tokens; (2) remove stop words (function words listed in the Python nltk English corpus), punctuation, and digits; (3) drop tokens that show up in more than $65 \%$ of the corpus and less than 30 documents; and (4) stem all remaining terms. In doing so, we follow standard feature selection practice. Note also that our findings are robust to alternative decisions regarding feature selection.
} 
often? Figure 2 provides an illustration of the politically relevant topics that were classified by the model within the sermon corpus. Specifically, the figure displays two interpretations of topic prevalence. The left panel illustrates the proportion of sermons where a particular political topic is among the three most probable topics in a given sermon. The most prevalent of the 21 political topics, according to this metric, is Economy which is among the top three most probable topics discussed

in $7.2 \%$ of the sermons in our corpus. We also find that Welfare, War, Homosexuality, Evolution, Abortion, and Civil Rights are among the most prevalent of the political topics.

Figure 2: Political topic prevalence
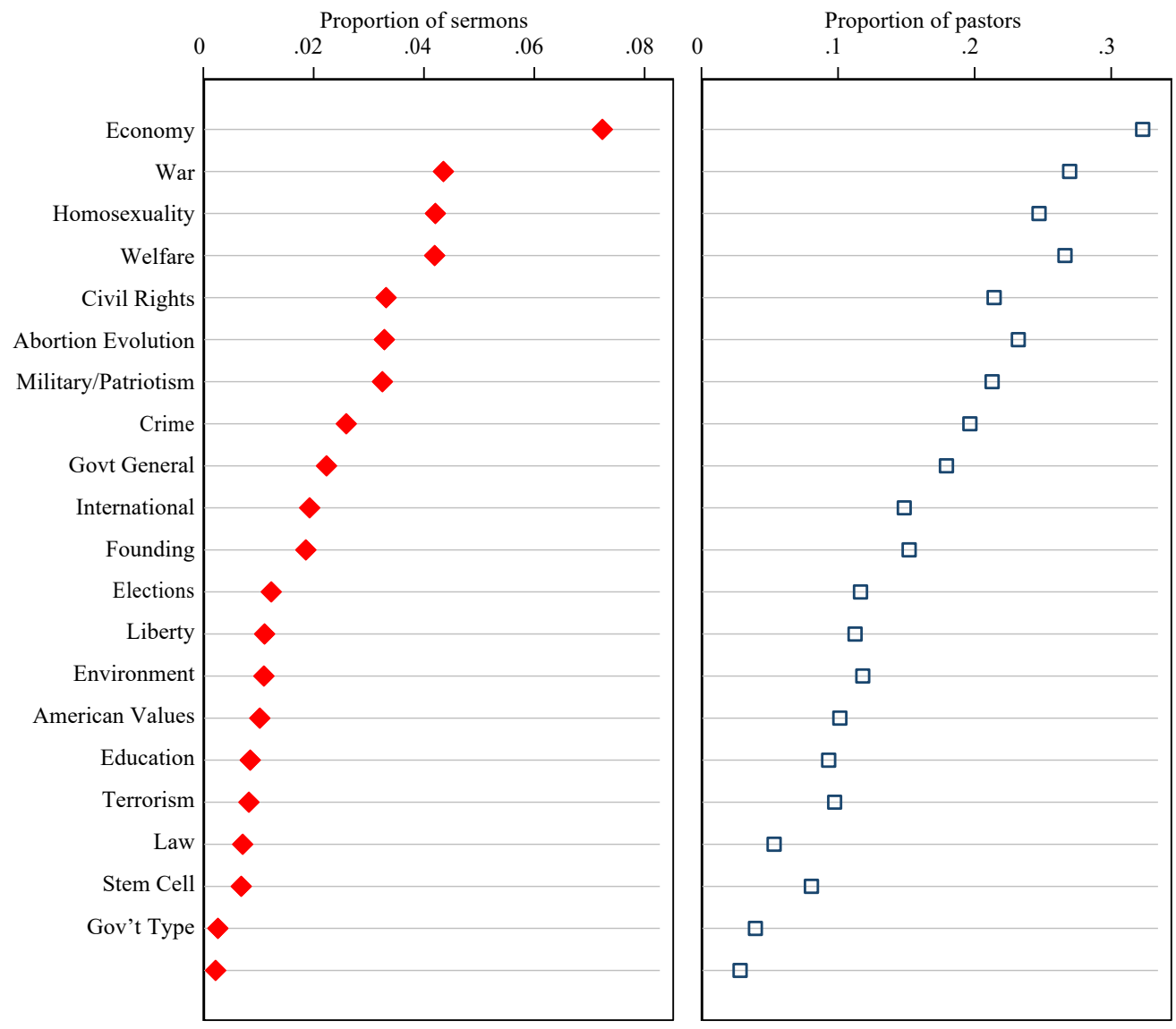

The left panel shows the proportion of sermons where at least one political theme is among the three most probable topics for that sermon. The right panel displays the proportion of pastors who delivered at least one sermon where a given political topic was among the top three likely topics. Topics in the left panel are sorted in descending order of prevalence, while the right panel follows the same variable ordering.

As an alternative metric, the right panel of Figure 2 displays the proportion of pastors who 
have delivered at least one sermon that contains a given political topic within the three most likely topics. We find very similar topic prevalence rankings when using this metric. We find that $32.3 \%$ of pastors authored at least one sermon that focused substantively on matters related to the Economy, while the next set of most prevalent political topics are essentially identical to those shown in the left panel. Using the pastor-level metric, we find that $70.7 \%$ of pastors delivered at least one sermon where any political topic was among the top three most likely themes. In some ways, these common topics map well onto survey research on pastors and the faithful. Past research has found high rates of reported discussions on welfare and civil rights (Djupe and Neiheisel 2008; Guth et al. 1997), which are also common topics in our data. However, other topics where pastors report frequent discussions, such as the environment, education, and family problems, occur far less often in results. We can also identify higher order groupings of these topics into meta-topics, such as moral issues, social justice and general government discussions.

What do discussions of these types of issues look like in the sermons? We read the sermons with the highest probability of any of our central topics to examine how these issues were framed. As one might expect, many sermons approach issues like Abortion and Homosexuality from a socially conservative perspective-with some more extreme in their outlook than others - but also with a clear political message to the congregants. For instance, one Baptist pastor concluded his sermon with the following piece of advice:

We must be politically involved and vote pro-life, no matter if you are a Democrat or a Republican. How dare we cast votes for people because of economic reasons, social security, or any other reason and not stand up for the unborn!

Homosexuality is often discussed as a sinful act and not as an identity. For example, an Evangelical pastor described those who are "caught in the sin of homosexuality" as being gay by choice and that they can change their "lifestyle" at any given moment. From a political point of view, homosexuality is framed as a product of public policy encroaching on traditional family values. Same-sex marriage is largely condemned. In general, sermons that are classified as highly probable of containing these moral issue topics often express a sense of moral warfare in American politics and society. As another sermon notes: 
As we move into the 21 st century, should the Lord tarry, I think probably the next civil war fought in America, not fought with guns and bullets, but fought with editorials and laws, will be the fight over abortion and acceptance of homosexuality.

Social justice themes are also present in the corpus. Sermons with a large share of words that are related to Civil Rights emphasize the virtue of racial equality. For instance, after clarifying that racism is still a scourge on American society, one pastor provides a religiously inspired condemnation of racism:

One of the greatest weapons of Satan is division. Simply because if he can divide he conquer [sic], and the fact is, there is only one race, the human race! People may have white skin, black skin, brown skin, yellow skin, red skin, or any other color skin, they may have different ethnic backgrounds, but they are all part of the same race, the human race!

Discussions of welfare and poverty often focus on explaining how God could allow people to be poor and how to learn from observing poverty. Other pastors discuss how wealth and poverty are not signs of Godliness. Discussions of the Good Samaritan are common, as are religious obligations to care for the poor. For instance:

The truth of the matter is it's not enough to give charity. It is our duty to do our share to see to it that we build a society where charity will not be unnecessary, a society where no sick person will go unattended, no hungry person will go unfed, no one is poorly housed, no able-bodied person will go without adequate employment, and good schools will be provided for all.

Other political discussions range widely from connections between war and biblical stories to the encouragement of parishioners to turn out to vote in order to condemn specific acts by the government or political leaders. Overall, these results suggest discussions of political topics occur in religious speech, but that most pastors frequently give sermons without any discussion of 
politics.

\section{Model validation and evaluation}

How else might we validate that these topics are actually capturing discussions in sermons? The descriptive labels and manual review of sermons with a high probability of containing a given political topic that are offered in Section 4 provide an initial demonstration of the semantic validity

Figure 3: Topic labels and similarities

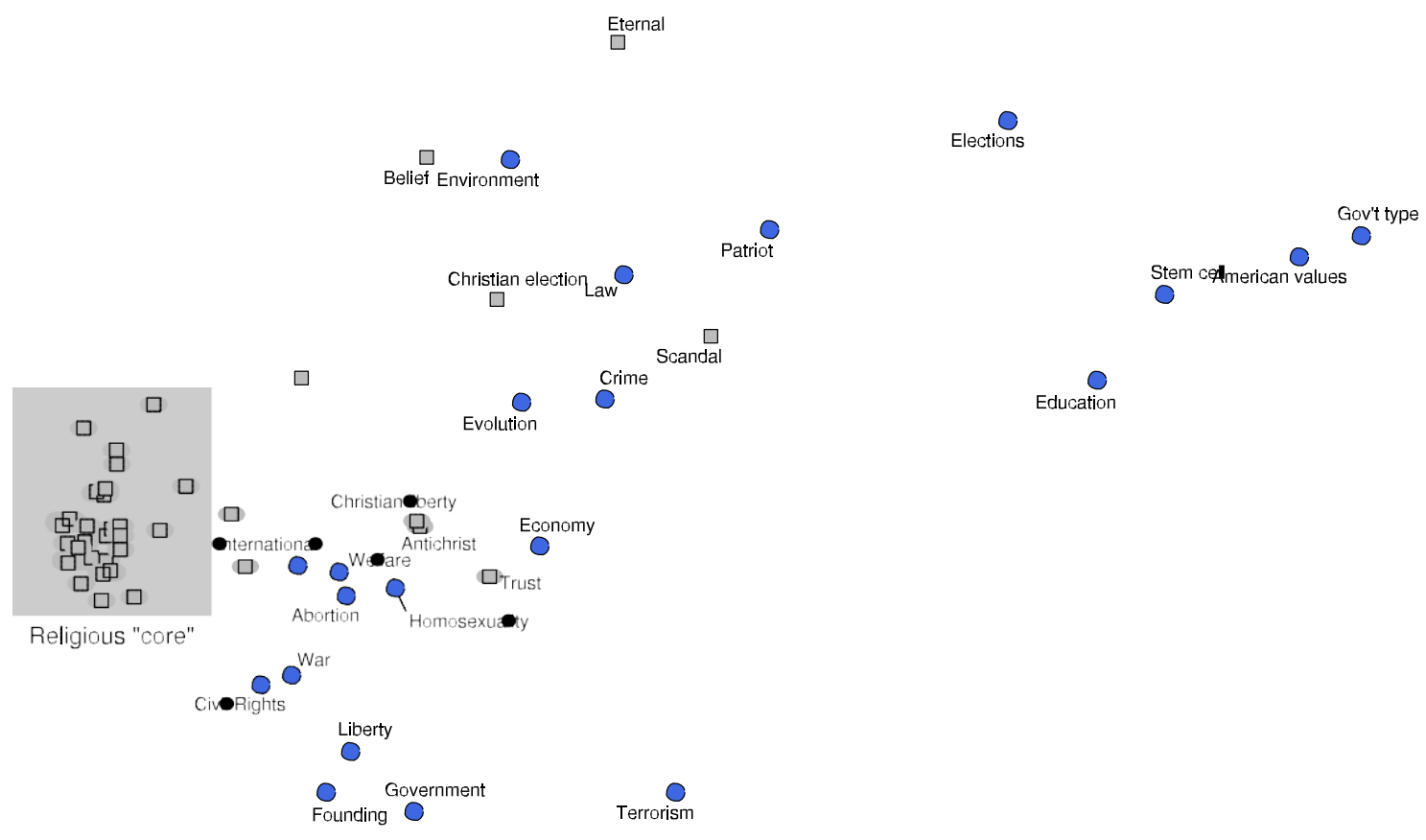

$\begin{array}{ll}\text { Homosexuality } & \text { homosexu, sexual, marrige, men, sex } \\ \text { International } & \text { christian, muslim, islam, religion, son } \\ \text { Law } & \text { court, shall, joshua, wit, stand } \\ \text { Liberty } & \text { freedom, free, nation, christian, law } \\ \text { Military/Patriotism } & \text { solder, nation, memori, remember, war } \\ \text { Stem Cell } & \text { human, cell, research, clone, embryo } \\ \text { Terrorism } & \text { muslim, islam, christian, hate, america } \\ \text { Gov't type } & \text { govern, christian, nation, radic, poor } \\ \text { War } & \text { war, enemi, battl, power, fight } \\ \text { Welfare } & \text { poor, poverti, rich, help, money }\end{array}$

The top panel of this figure illustrates topic similarity by displaying Jensen-Shannon distances which are projected onto a 2D space with the use of multi-dimensional scaling. Labels marked as blue circles correspond to political topics, while grey squares relate to religious themes. Topics that use similar words are closer together and vice-versa. The bottom panel displays the full list of estimated political topics (in alphabetical order) and provides the top 5 stemmed keywords for each topic. 
of the model. ${ }^{7}$ In this section, we offer further support for this validity criterion by: (1) examining the degree to which the estimated political topics meaningfully relate to one another (i.e. semantic similarity) (Quinn et al. 2010); and (2) whether the attention given to certain political themes over time corresponds to relevant external events (i.e. predictive validity).

\section{Semantic similarity}

Given that a "topic" in the L-LDA model is a probability distribution of words given the topic, we can represent the "semantic similarity" between topics as the distance between probability distributions. In this study, we accomplish this task by measuring the divergence (JSD) between topics (see Endres and Schindelin 2003). Similar topics share a smaller JSD value, while dissimilar topics have larger JSD values. The top panel of Figure 3 illustrates the semantic similarity of the estimated topics by mapping the pairwise JSD distances onto a two dimensional space. The 21 politically-relevant topics are labelled and represented by blue circles, while the remaining 40 religious topics are shown as grey squares.

The relationships between topics conform with the discussion of meta-themes generally discussed in the literature. First, we can discern a clear cluster of most religious topics (the "Religious core") which is semantically distinct from the political topics, meaning that the model picks up semantic differences when pastors discuss entirely religious versus religious-political themes. Second, among the political topics, interesting clusters emerge. Along the bottom portion of the figure lie topics related to American government and security (e.g., Founding, Liberty, Patriotism, Elections, American values, Terrorism). Surrounding the religious core are political topics that are typically related to moral issues (e.g., Abortion, Homosexuality) and social justice (e.g., Civil rights, Welfare). Moving along the top portion of the figure, we can see political topics that involve more general issues (e.g., Crime, Education) and science (e.g., Environment, Stem cell). Overall, we are satisfied with how such a simple model, based on word co-occurrences, can distinguish political speech from religious preaching and allows for the emergence of meaningful higher-order clusters of political themes.

\footnotetext{
${ }^{7}$ The authors also confirmed political content and topics by reading a random selection of 5\% of sermons with high probability of political content.
} 
Figure 4: Predictive validity of selected topics.

(a) Politics (General)

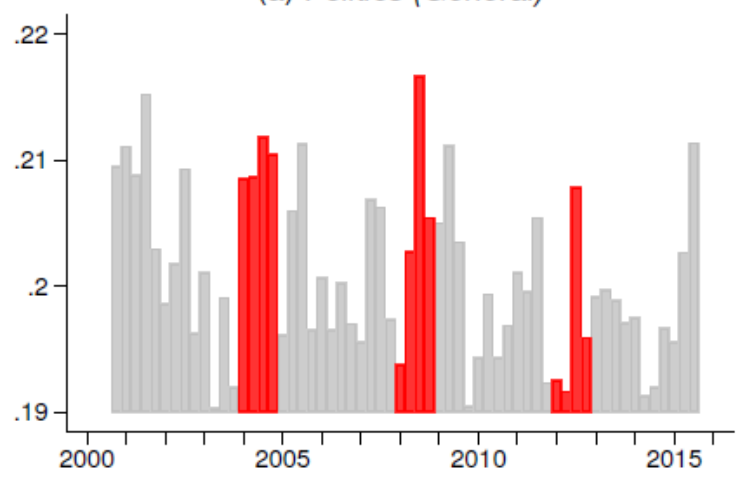

(c) Abortion

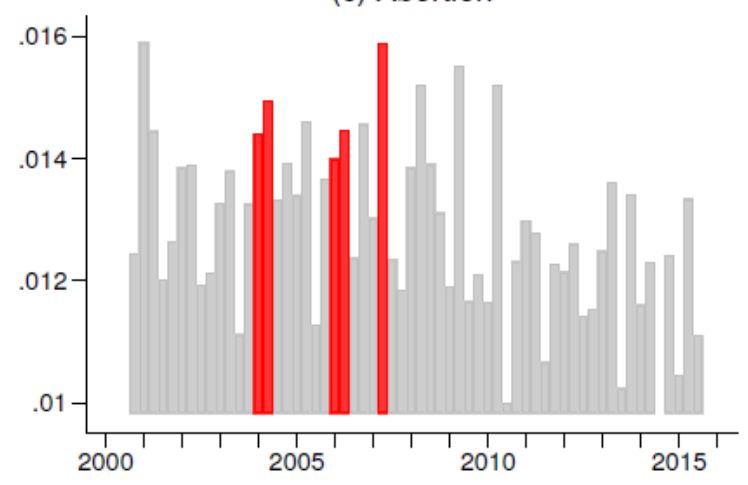

(b) Economy

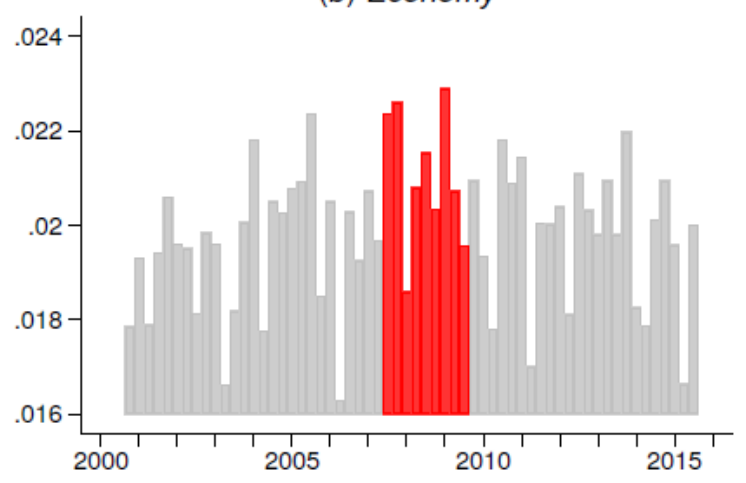

(d) Homosexuality

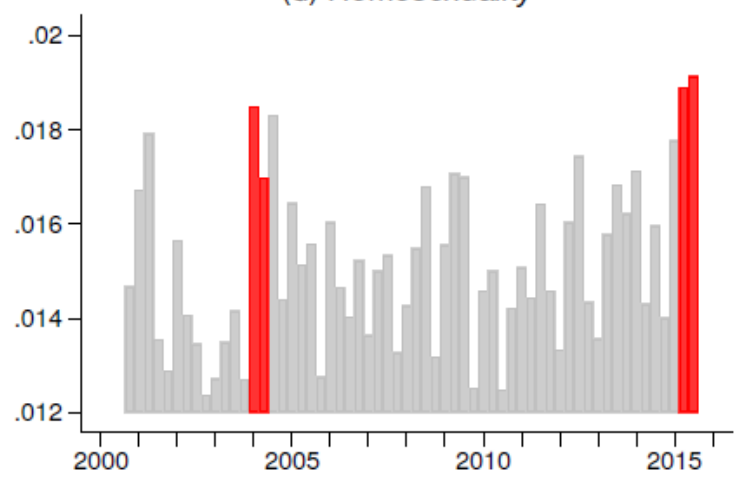

Note: This figure illustrates the average quarterly topic proportions of four political topics (General politics, economy, abortion, and homosexuality) over the period 2000q4-2015q3. Periods of interest are highlighted in red.

\subsection{Predictive validity}

We next validate the data by comparing the prevalence of each topic to external events, essentially evaluating the predictive probability of the topic models (see Quinn et al. 2010). We should expect elevated discussions of a given theme during a period of time when a particularly relevant event has occurred which would prompt discussion of the issue. Figure 4 displays the mean topic probability of four political themes (General politics, Economy, Abortion, and Homosexuality) for each yearly quarter over the period 2000q4 to 2015q3, with quarters darkened where we would expect higher values, given real world events.

How well do our topics perform in terms of predictive validity? Beginning with the Politics (General) topic, which is a summation of all 21 political topics estimated by the model, we see that spikes in discussion seem to coincide with Presidential election seasons (2004, 2008, 
2012) as well as salient national events (e.g., 9/11). How about the Economy? We find a bulge in discussion of economic related themes around the time of the 2008 financial crisis. For Abortion, we see anescalation of discussion around major court cases: a series of federal cases in Q1 and Q2 of 2004 (including Nat'l Abortion Fed'n v. Gonzales, Ayotte v. Planned Parenthood in Q1 and Q2 of 2006, and Gonzales v. Carhart in Q2 of 2007). Further, we see increased discussions of Homosexuality around the time of the first legal gay marriage in the United States in May 2004 and the Obergefell $v$. Hodges ruling in June 2015, which essentially legalized gay marriage across the United States.

Overall, relying on semantic and predictive validation procedures, we are confident that our topics are picking up the underlying subject matter within the corpus in a consistent and cohesive manner. At the same time, there is noise in these figures, with increases and decreases in discussions outside national events, suggesting that pastors employ political discussions not just when issue salience increases, but also because of their preferences and local concerns.

\section{What factors are associated with differences in pastoral discussion of major political themes?}

Given the high level of variation that we find in the discussion of overall discussion of political issues and on individual topics, what pastor-, church- and community-level factors help explain if and how pastors discuss politics? We examine this question by combining salient political themes and meta-data from the SermonCentral corpus with demographic and electoral data for each church's surrounding area. ${ }^{8}$

\subsection{Dependent variables: A set of politically relevant themes in sermons}

We examine the overall level of political discussion (Politics (General)), as well as five sub-

\footnotetext{
${ }^{8}$ The sample of sermons used in the statistical analysis is smaller than the set used in the topic model. We also dropped observations from churches in the following states because we could not locate precinct voting data: Arkansas, Kentucky, Maine, Montana, North Dakota, Oregon, Rhode Island, Utah, West Virginia, Wyoming, and Washington, D.C. Therefore, the statistical analysis in Section 6 includes 100,525 sermons by 5,042 pastors from 40 U.S. states.
} 
topics: the discussion of the Economy, two moral concern topics (Homosexuality and Abortion), and two social justice topics (Civil Rights and Welfare) as our dependent variables. In each case, we measure the level of discussion as the proportion of words devoted to the relevant topic in Figure 3. For the Politics (General) measure, we use the proportion of words devoted to any of the topics listed in Figure 3.

\subsection{Pastor, church, and community-level data}

Our primary independent variables include information about pastor, church, and the area surrounding the churches. First, when considering church- and pastor-level factors, we utilize a variety of self-reported information from the clergy, including denominational information from each pastor, which we aggregated into general categories according to the Handbook of Denominations in the United States. We coded race and gender information using photos and the U.S. Census' list, which provides gender and race probabilities of each first and last name of those names where there are more than 100,000 people with that name in the United States (see Sumner 2018). ${ }^{9}$

Second, we collected information on key demographic and economic information for areas surrounding our sample of churches from the U.S. Census. However, defining the appropriate area or "neighborhood" associated with a particular church using Census data for a geo-coded church is not straightforward. To provide a reasonable estimate of the areas that could supply potential congregants to a given church, we relied on measures from the U.S. Department of Transportation 2009 Household Travel Survey (Santos et al. 2011, p.13), which found that the average person trip length to "school/church" is 6.3 miles. Using this information, we defined a church's "neighborhood" as all of the Census block groups intersecting a 10 mile radius around the church (for more information on the construction of the geographic measures, see Section D of the Appendix). With the neighborhood estimate in hand, we aggregated - using the mean-

\footnotetext{
${ }^{9}$ We were unable to determine the gender of 225 clergy because of first initials or rare names. When there was a conflict between the human coding from Crowdflower and the names list, the authors hand-coded the information or using web searches to find the information.
} 
information on the following variables: natural log of the total population (Geo: Pop.), proportion of white residents (Geo: White) and median income (Geo: Income). To measure the political leaning of a given neighborhood, we also incorporate voting data from the 2008 Presidential election (Ansolabehere, Palmer, and Lee 2015) and include all precincts that intersect the 10 mile radius for the church. We use the percentage of the two-party vote for President Obama in the 2008 election (Geo: Obama 08\%). Lastly, we record whether a given church is located in the U.S. South (Geo: South).

\subsection{Statistical Methods}

We utilize a fractional logit model because of the number of features of the SermonCentral data that complicate model selection. Our dependent variables are based on the proportion of words devoted to a particular topic and necessarily range from 0 to 1 , which precludes the use of OLS regression. In addition, we use sermon-level data with nested observations within pastors and communities. We operationalize the church "community" as the union of churches with overlapping neighborhoods (see Section D of the appendix for more information on constructing church communities). To address these two unique features of our data, we employ the fractional logit model, which is well-suited for dependent variables bound between [0,1] (Papke and Wooldridge 1996). As such, the models presented below provide estimates from fractional logit models of sermon-level data, with clustering on both the pastor and church "neighborhood."

\section{Variation in political discussions in churches}

While pastors often discuss political issues, there is also variation in who is more likely to include these discussions in their religious messages. Previous research has found that pastors respond to congregational and community preferences and denominational pressures and traditions, while also exerting their personal preferences in determining when and how to discuss political issues.

In general, clergy view their own role as primarily to tend to the flock by serving and 
preserving their congregation, including pleasing and serving existing members of her church and attracting new members (Djupe and Gilbert 2003; Olson 2000). As such, clergy that view their congregations as politically active are more likely to be politically active themselves (Guth et al. 2003). These findings suggest that the characteristics of congregations and the community have the potential to influence both the emergence and form of political discussions in sermons; as Djupe and Olson note, "While ministering to local concerns might simply involve a particular agenda construction, it also might entail identification with the particular values of the community first and the religious organization second" (2010, 275; emphasis in original).

We expect that the socio-economic and political characteristics of the community around the church might shape political discussions. Generally, individuals with more socio-economic resources, including income and education, are more political engaged and active (Farris and Holman 2014). These patterns would suggest that the income and education levels of the community will have a positive relationship with political discussions. Research also suggests that low socio-economic status areas attract clergy more interested in political change and social justice (Olson 2000). Clergy in areas with poor or minority residents may be particularly likely to discuss social justice issues. The political beliefs of the community may also shape pastor behavior, with more political discussions of social welfare issues in more liberal areas and increased discussions of moral concerns in conservative areas.

Denominational affiliation is certainly important in determining the level of political discussions by clergy (Olson 2000; Djupe and Gilbert 2003). Those denominations that focus more on the public role of religion and social gospel teachings, such as mainline Protestants, provide a natural gateway for the discussion of political issues in a religious context (Guth et al. 1997). As such, mainline Protestant pastors may be more likely to discuss political issues, particularly those issues relating to social justice concerns. Evangelicals often focus religious attention on individual salvation and other-worldly concerns. On one hand, this would suggest that there will be lower levels of discussion of political issues in Evangelical churches, particularly when compared to mainline Protestant churches. On the other hand, civic gospel principals may push Evangelical pastors to engage in politicking, particularly around moral issues. Thus, we expect 
that Evangelical pastors will engage in more political discussions around moral issues, but fewer discussions of social justice issues and general political discussions.

Clergy characteristics may also play a role in the emergence of political speech in sermons. In general, churches and religious leaders are well respected in the United States and are "important factors within American public life" (Smidt 2016, 2). Clergy also often have a significant degree of autonomy and can shape the foci of sermons and discussions within their congregations. Descriptive characteristics may also matter. Indeed, theories of descriptive representation suggest that characteristics like race and gender may shape the interests and foci of

clergy. For example, female clergy are more likely to speak about gay marriage (Deckman, Crawford, and Olson 2008; Friesen and Djupe 2017) and Black clergy are more likely to discuss issues associated with race and civil rights. Women and minorities are attitudinally more likely to support social justice policies and are more likely to benefit from these policies (Holman 2016; Ondercin 2017).

\subsection{Results}

What factors are associated with higher or lower levels of political discussion by clergy? Figure 5 (and a related table in Appendix G) illustrates the estimates from the series of fractional logistic regression models described in Section 6.3 that seek to explain variation in a sermon's share of words that are related to politics generally as well as to a set of relevant political themes. The figure shows the coefficients (log odds) and confidence intervals (99\%, 95\%, and 90\%) of the covariates described in Section 6.2. The results are presented in thematic groups. Panel (a) displays the results of models that explain discussion of politics in general and the economy. Panel (b) presents models which explain variation in sermon attention to moral issues such as abortion and homosexuality. Last, Panel (c) shows the results of models focused on variation of discussion on social justice matters such as civil rights and welfare. 
(a) Politics (General) and Economy

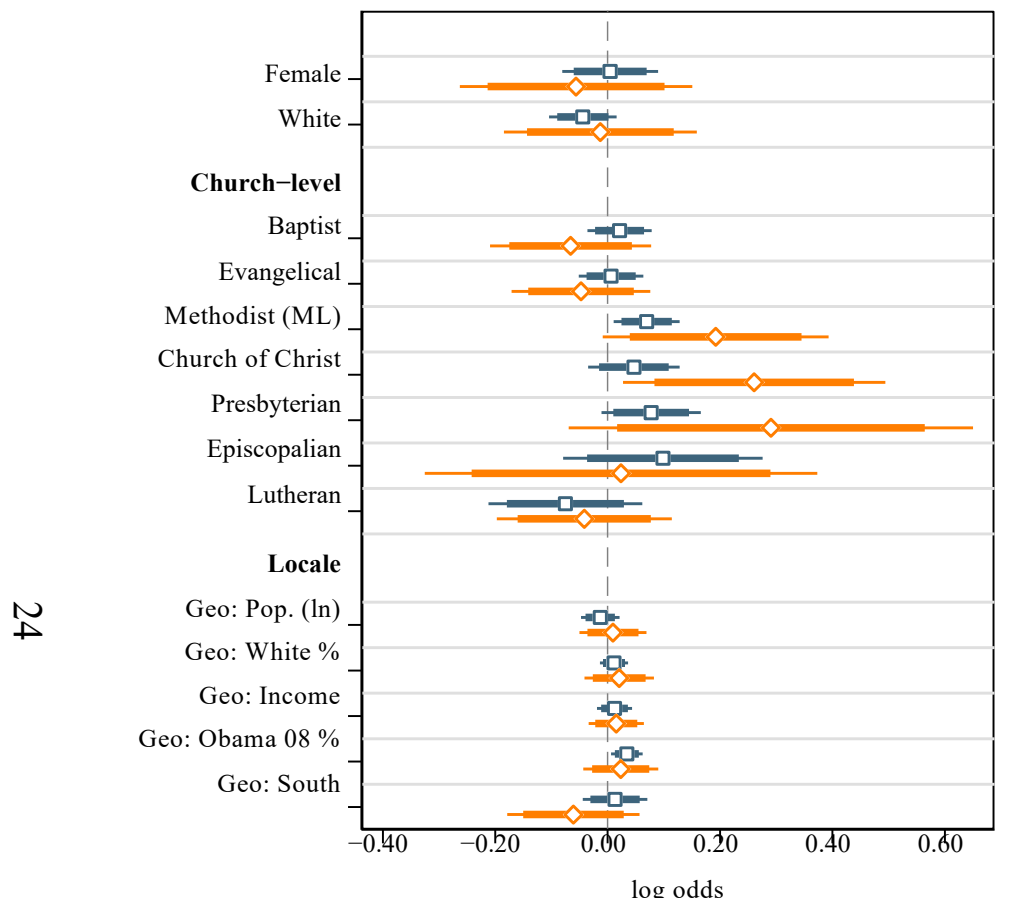

(b) Moral Issues (Abortion and Homosexuality)

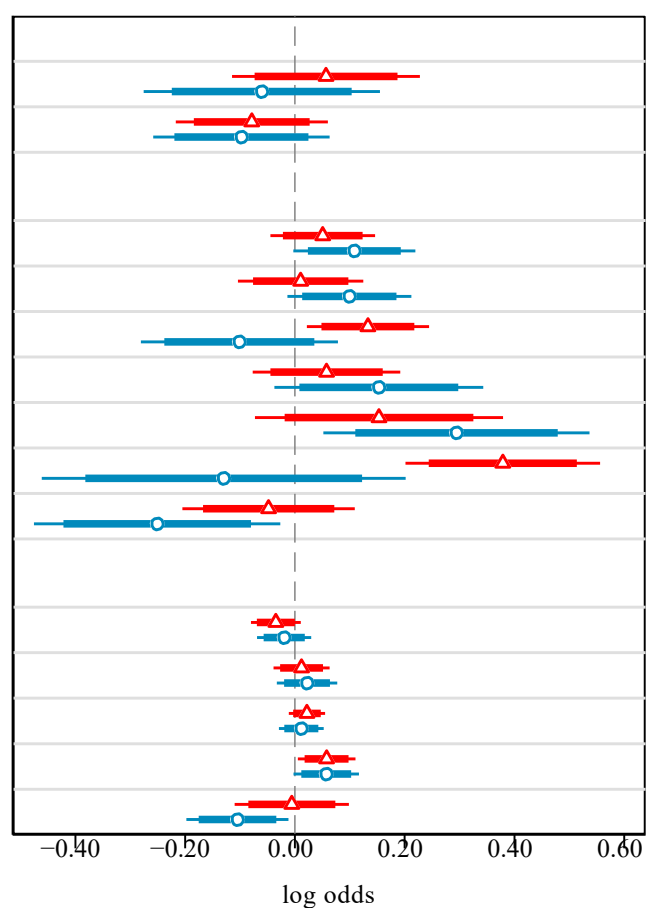

(c) Social Justice (Civil Rights and Welfare)

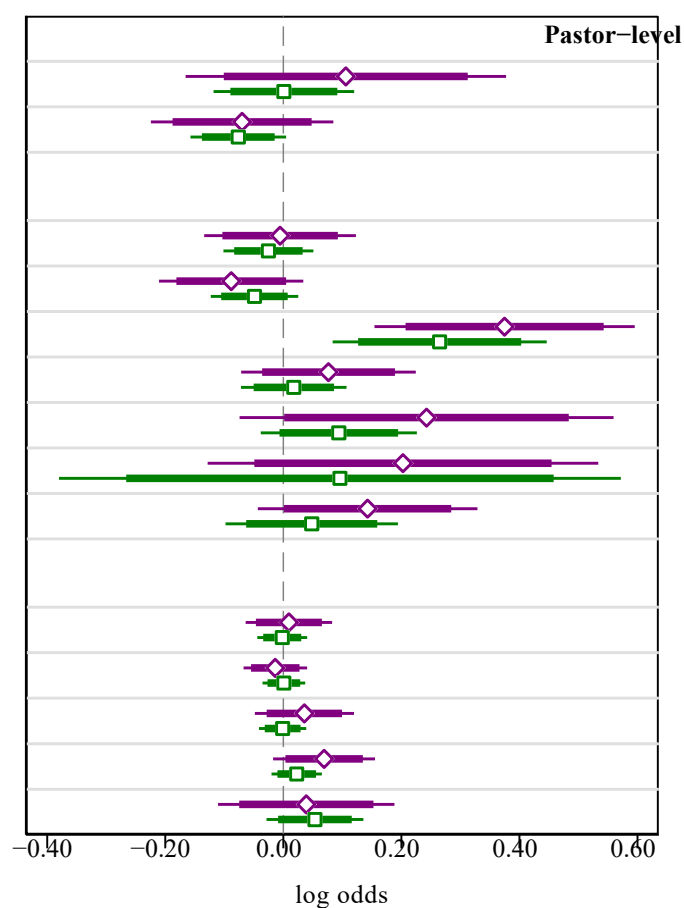

\begin{tabular}{|l|l|}
\hline$\square$ Politics $\diamond$ Economy & Abortion \\
\hline
\end{tabular}

Homosexuality

c

Civil Rights

W@fare

口

Figure 5: Explaining variation of politically-relevant discussion in sermons. This plot illustrates the results of the fractional logistic regression models described in Section 6.3. Standardized coefficients (log odds) and confidence intervals [99\%, 95\%, 90\%] are displayed. Regular coefficients are displayed for dummy variables. The figure displays model results for six (6) dependent variables. Panel (a) shows the results for Politics (top, blue, square) and Economy (bottom, orange, diamond). Panel (b) displays the estimates for Abortion (top, red, triangle) and Homosexuality (bottom, light blue, circle). Panel (c) illustrates the estimates for Civil Rights (top, purple, diamond) and Welfare (bottom, green, square). Note that church size statistics are only reported in the appendix. 
We first examine the models presented in Panel (a): general political and economy-related discussions within sermons. Starting with the results for General Politics, we do not find any pastor gender differences in the proclivity to discuss politics in general. With respect to denomination relationships, there is no statistically significant difference in general political discussion between sermons from the Evangelical traditions with those of the "other Christian" baseline category (that is, non-Evangelical and non-Mainline Protestant churches). However, Methodist and Presbyterian pastors employ a higher share of words that deal with political themes in their sermons. We find few effects for the location of a church except that sermons from churches in more political liberal locales contain more words related to politically relevant themes. In many ways, these findings depart from survey research, which often finds large denomination differences in who engages in political discussions.

The next model in Panel (a) estimates variation in the share of words related to the Economy. While there is little evidence of relationships between the gender or race of the pastor and sermon topics, similar to General Politics, we again find denomination variations. Namely, the results suggest that sermons from Mainline Protestant churches are positively and significantly related with the share of economic discussions, which is largely consistent with the extant scholarship. We also find no differences in the community; that is, pastors in poorer (or richer) places are no more likely to discuss economic issues.

Next, we review the results of models in Panel (b) associated with the moral concerns issues of Abortion and Homosexuality. Again, the results of the statistical tests suggest that denomination shapes patterns of these political discussions. Specifically, mainline Protestant pastors from Methodist, Presbyterian, and Episcopalian sermons are positively associated with abortion discussions, departing from our expectations about Evangelical activism on the issue. We do find that churches from both the Evangelical and Mainline traditions are statistically different from other pastors in how they communicate the issue of homosexuality. The population of the area around the church is negatively associated with discussions about abortion. Pastors in more affluent neighborhoods are more likely to mention abortion in their sermons. Further, the political liberalness of a church's locale has a positive relationship with the 
share of words within a sermon that are related to abortion and homosexuality. Sermons by Southern pastors discuss homosexuality less than their non-Southern counterparts.

The last set of models focus on the discussion of Civil Rights and Welfare in religious sermons; the results are illustrated in Panel (c). We find little evidence of pastor demographic effects on social justice themes. However, the results suggest that white pastors are less likely (10\% error level) to include welfare themes in their sermons. With respect to denomination relationships, Evangelicalism is associated with fewer discussions of civil rights and welfare, while Mainline Protestant denominations (particularly Methodists) are associated with higher level of discussions about both civil rights and welfare than the baseline. There are mixed church- and locale-related results on how much social justice issues are discussed in sermons: churches in more liberal locales produce sermons with a greater use of words related to civil rights, while Southern sermons discuss welfare more.

\section{Discussion}

In general, churches and religious leaders are well respected in the United States and are "important actors within American public life" (Smidt 2016, 2). Understanding the political discussions within religious sermons is thus an essential component to understanding politics more generally in America. In this paper, we use a large corpus of religious sermons and a computational text analysis process to examine these discussions. Our research provides a next logical extension to a robust body of scholarship that has evaluated pastor political behavior through surveys, observations, and interviews. We build on these avenues of research in our evaluations; in turn, our results could inform future survey, observation, and interview research.

Methodologically, we provide innovations in how we utilize the user-generated tags, crowd sourcing, and elite coding to generate topics in a dataset characterized by both class imbalance and a large number of topics. We then use multiple steps to validate these topics. Others seeking options for identifying rare language in a large corpus of text might utilize the methods outlined here or adapt them for other approaches. And researchers interested in the 
qualitative discussions of political issues could also use our trained topic model as an information retrieval tool to help narrow down the large corpus of sermons for analysis.

Qualitative evaluations of the sermons suggest that pastors are willing to post sermons with content that is controversial, political, and related to current events. Yet, the results presented here are, like much of the scholarship on religious elites, based on a convenience sample. We are not confident that we understand what might prompt a pastor to post anything on SermonCentral or not, or to post a specific sermon on the website, just as we do not know fully what causes individuals to post political information on social networking websites (Barberá and Rivero 2015). Future research might combine our large-n data with surveys of pastors (Calfano and Oldmixon 2018) to understand how they see their congregation's politics or to gather additional observational data on the parishioners themselves.

What our study cannot say is the effect of these sermons on the congregants in these churches. Yet, research demonstrates that the religious content of church discussions percolate to voters' attitudes (Deckman 2002; Cassese and Holman 2017) and political attitudes shape where people attend church (Margolis 2018, 2016). Experimental research might examine whether politically focused sermons shape political attitudes and behavior (Albertson 2015). Future research might also apply sentiment analysis to examine whether denomination, community, or pastor characteristics shape how political issues are discussed in religious settings (Krupnikov and Searles 2018).

Our work highlights the possibilities of applying new methodologies to long standing questions in political science. The intertwined nature of religion and politics in the United States is far from a new inquiry. Yet, applying new methods and approaches opens up new avenues of knowledge. That most pastors discuss political issues at least some of the time reaffirms the importance of churches as vehicles for political discussions, opinion formation, and socialization. 


\section{References}

Aaldering, Loes, and Daphne Van Der Pas. 2018. "Gender bias in leader stereotypes during campaign and routine times.” British Journal of Political Science: 1-21.

Albertson, Bethany. 2015. "Dog-whistle politics: Multivocal communication and religious appeals." Political Behavior 37 (1): 3-26.

Ansolabehere, Stephen, Maxwell Palmer, and Amanda Lee. 2015. Precinct-Level Election Data, 2002-2012. doi:1902.1/21919

Barberá, Pablo, and Gonzalo Rivero. 2015. "Understanding the political representativeness of Twitter users." Social Science Computer Review 33 (6): 712-729.

Benoit, Kenneth, et al. 2016. "Crowd-sourced text analysis." American Political Science Review 110 (2): $278-295$.

Boussalis, Constantine, Travis Coan, and Mirya R Holman. 2018. "Climate change communication from cities in the USA." Climatic change 149 (2): 173-187.

Brewer, Mark, Rogan Kersh, and R. Eric Petersen. 2003. “Assessing Conventional Wisdom about Religion and Politics." Journal for the Scientific Study of Religion 42 (1): 125-136.

Calfano, Brian, and Elizabeth A Oldmixon. 2018. "The Influence of Institutional Salience on Political Attitudes and Activism among Catholic Priests in the United States." Journal for the Scientific Study of Religion 57 (3): 634-643.

Calfano, Brian, Elizabeth A. Oldmixon, and Mark Gray. 2013. "Strategically Prophetic Priests: An Analysis of Competing Principal Influence on Clergy Political Action.” Review of Religious Research 56 (1): $1-21$.

Cassese, Erin, and Mirya R. Holman. 2017. "Religion, gendered authority, and identity in American politics." Politics and Religion 10 (1): 31-56.

Chapp, Christopher. 2012. Religious Rhetoric and American Politics: The Endurance of Civil Religion in Electoral Campaigns. Ithaca, NY: Cornell University Press.

Deckman, Melissa. 2002. "Holy ABCs! The impact of religion on attitudes about education policies." Social 
Science Quarterly 83 (2): 472-487.

Deckman, Melissa, Sue Crawford, and Laura Olson. 2008. "The politics of gay rights and the gender gap." Politics and Religion 1 (03): 384-410.

Djupe, Paul, and Amanda Friesen. 2018. "Moralizing to the Choir: The Moral Foundations of American Clergy.” Social Science Quarterly 99 (2): 665-682.

Djupe, Paul A., and Christopher P. Gilbert. 2002. "The Political Voice of Clergy.” The Journal of Politics 64 (2): 596-609.

- 2003. The Prophetic Pulpit: Clergy, Churches, and Communities in American Politics. London: Rowman \& Littlefield.

Djupe, Paul A., and Jacob R. Neiheisel. 2008. "Clergy Deliberation on Gay Rights and Homosexuality." Polity 40 (4): 411-435.

Djupe, Paul, and Laura Olson. 2010. "Diffusion of Environmental Concerns in Congregations across U.S. States.” State Politics \& Policy Quarterly 10 (3): 270-301.

Endres, Dominik Maria, and J. E. Schindelin. 2003. "A new metric for probability distributions." IEEE Transactions on Information Theory 49 (7): 1858-1860.

Evans, Heather, Victoria Cordova, and Savannah Sipole. 2014. "Twitter style: An analysis of how house candidates used Twitter in their 2012 campaigns.” PS: Political Science \& Politics 47 (2): 454-462.

Friesen, Amanda, and Paul Djupe. 2017. "Conscientious Women: The Dispositional Conditions of Institutional Treatment on Civic Involvement.” Politics \& Gender 13 (1): 57-80.

Glazier, Rebecca. 2015. "Bridging Religion and Politics: The Impact of Providential Religious Beliefs on Political Activity.” Politics \& Religion 2015 (3): 458-487

Gower, J. C. 1966. "Some distance properties of latent root and vector methods used in multivariate analysis." Biometrika 53:325-328.

Greene, Zachary, and Diana O’Brien. 2016. "Diverse parties, diverse agendas? Female politicians and the parliamentary party's role in platform formation.” European Journal of Political Research 55 (3): 435-453. 
Griffiths, Thomas, and Mark Steyvers. 2004. "Finding scientific topics." Proceedings of the National Academy of Sciences 101:5228-5235.

Grimmer, Justin. 2013. Representational style in Congress: What legislators say and why it matters. Cambridge University Press.

Grimmer, Justin, and Brandon Stewart. 2013. "Text as Data: The Promise and Pitfalls of Automatic Content Analysis Methods for Political Texts.” Political Analysis 21 (3): 267-297.

Guth, James, et al. 1997. The Bully Pulpit The Politics of Protestant Clergy. Lawrence, KS: University of Kansas Press.

Guth, James, et al. 2003. "The political activity of evangelical clergy in the election of 2000: A case study of five denominations." Journal for the Scientific Study of Religion 42 (4): 501-514.

Holman, Mirya R., and Kristin Shockley. 2017. "Messages from Above: Conflict and Convergence of Messages to the Catholic Voter from the Catholic Church Hierarchy." Politics and Religion 10 (4): 840-861.

Japkowicz, Nathalie, and Shaju Stephen. 2002. "The class imbalance problem: A systematic study." Intelligent Data Analysis 6 (5): 429-449.

Jelen, Ted G. 1993. “The Political Consequences of Religious Group Attitudes.” The Journal of Politics 55 (1): 178-190.

Krupnikov, Yanna, and Kathleen Searles. 2018. "New Approaches to Method and Measurement in the Study of Political Communication Effects.” Political Communication: 1-5.

Liu, Tie-Yan, et al. 2005. "Support vector machines classification with a very large-scale taxonomy." $A C M$ SIGKDD Explorations Newsletter 7 (1): 36-43.

Margolis, Michele. 2016. "Cognitive Dissonance, Elections, and Religion: How Partisanship and the Political Landscape Shape Religious Behaviors.” Public Opinion Quarterly 80 (3): 717-740.

— . 2018. "How Politics Affects Religion: Partisanship, Socialization, and Religiosity in America." The Journal of Politics 80 (1): 30-43.

Muddiman, Ashley, Shannon McGregor, and Natalie Stroud. 2018. “(Re) Claiming Our Expertise: Parsing 
Large Text Corpora With Manually Validated and Organic Dictionaries.” Political Communication: 1-13.

Ng, Andrew, and Michael Jordan. 2002. “On discriminative vs. generative classifiers.” In Advances in neural information processing systems, 841-848.

Ondercin, Heather 2017. "Who is responsible for the gender gap? The dynamics of men's and women's democratic macropartisanship, 1950-2012.” Political Research Quarterly 70 (4): 749-761.

Presser, Stanley, and Linda Stinson. 1998. "Data collection mode and social desirability bias in self-reported religious attendance." American Sociological Review 63 (1): 137-145.

Roberts, Margaret, et al. 2014. "Structural Topic Models for Open-Ended Survey Responses.” American Journal of Political Science 58 (4): 1064-1082.

Rubin, Timothy, et al. 2012. "Statistical topic models for multi-label document classification." Machine Learning 88 (1): 157-208.

Santos, Adella, et al. 2011. Summary of travel trends: 2009 national household travel survey. Tech. rep. U.S. Department of Transportation.

Scheitle, Christopher, and Nicole Cornell. 2015. "Hearing Clergy Speak About Social and Political Issues: Examining the Effects of Religious Tradition and Personal Interest.” Social Science Quarterly 96 (1): 148-160.

Smidt, Corwin. 2016. Pastors and Public Life: The Changing Face of American Protestant Clergy. New York: Oxford University Press.

Smith, Amy Erica. 2019. Religion and Brazilian Democracy: Mobilizing the People of God. Cambridge University Press.

Sumner, Jane Lawrence. 2018. “The Gender Balance Assessment Tool (GBAT): A Web-Based Tool for Estimating Gender Balance in Syllabi and Bibliographies.” PS: Political Science \& Politics 51 (2): 396-400.

Thomas, Jeremy, and Andrew Whitehead. 2015. "Evangelical Elites' Anti-Homosexuality Narratives as a Resistance Strategy Against Attribution Effects.” Journal for the Scientific Study of Religion 54 (2): 
345-362.

Warren, Rick. 1995. The Purpose Driven Church: Every Church Is Big in God's Eyes. Grand Rapids, MI: Zondervan.

Wilcox, Clyde, and Carin Larson. 2006. Onward Christian Soldiers: The religious Right in American politics. Boulder, CO: Westview Press.

Woolfalk, Katherine. 2013. "Essays on Social Contexts and Individual Politics: The Political Influence of Religious Institutions and Ethno-Racial Neighborhood Contexts.” PhD thesis. 